\title{
Effect of the Surface Finishing Methods on Particleboard Volatile Organic Compounds and Formaldehyde Emission
}

\author{
Feng Chen, ${ }^{\mathrm{a}, *}$ Jun Shen, ${ }^{\mathrm{b}, *}$ and Xinghua $\mathrm{Xia}^{\mathrm{a}}$
}

\begin{abstract}
Chemical contaminants from wood-based panels, such as volatile organic compounds (VOCs) and formaldehyde, are the main sources of indoor air pollution. The particleboards were used as the substrate and five common finishing methods, including melamine-impregnated paper, high-density polyethylene decorative film, wood veneer, polypropylene water borne paintings coatings, and polyurethane water borne paintings coatings, were selected for this study. The emission curves in the first $6 \mathrm{~h}$ and the equilibrium concentrations of the total volatile organic compounds (TVOC) and formaldehyde processed with the finishing wood-based panel method for $24 \mathrm{~h}$ were obtained and measured using an airtight environmental chamber. The ingredients of the VOCs were investigated using the small chamber method and gas chromatography and mass spectrometry (GC/MS). The results indicated that the finishing methods were effective for reducing the emissions of TVOC (except the water borne coating) and formaldehyde of the particleboards. High density polyethylene film was the best finishing material to reduce the release of TVOC. The concentration of the veneered particleboard from the third to the tenth hour was higher than the unfinished particleboards. The veneered particleboard released six volatile ingredients to a lesser extent than the unfinished particleboard.
\end{abstract}

Keywords: Particleboard; Finishing method; VOCs; Formaldehyde; GC/MS

Contact information: a: School of Art and Design, Taizhou University, Taizhou 318000, China; b: College of Material Science and Engineering, Northeast Forestry University, Harbin 150040, China;

*Corresponding author: c.f84@hotmail.com; shenjunr@163.com

\section{INTRODUCTION}

Formaldehyde and volatile organic compounds (VOCs) are released from woodbased panel materials (e.g., particleboard, plywood, and medium-density fiberboard), which are mainly hot-pressed with wood particles or wood fibers, urea-formaldehyde resin (UF), and some other ingredients (Yrieix et al. 2010; Liang et al. 2016; Zhao et al. 2018). The VOCs, which include hydrocarbons, organic halides, organic sulfides, carbonyl compounds, organic acids, and organic peroxides, can be present in the air in the form of steam at normal temperatures (Rudnicka et al. 2019). However, the toxicity of VOCs, which will influence the skin and mucous membranes or cause chronic damage to the human body, has received widespread concern (Norback 2009; Niu et al. 2016). The World Health Organization (WHO) defines TVOC as those whose melting point is below room temperature and whose boiling point ranges from 50 to $260{ }^{\circ} \mathrm{C}$ (Mølhave et al. 1997). In many disqualified decoration constructions, TVOC and formaldehyde concentrations exceeded the standard by a factor of dozens (Du et al. 2014; Chi et al. 2016). Hence, controlling the emission of VOCs and formaldehyde in decoration materials, such as particleboards, has become the focus of scholars. 
There has been some research on the effects of the hot-pressing condition, adhesive, heat treatment, and secondary processing of panels on VOCs and formaldehyde emissions of particleboards. In those reports it has been shown that the hot-pressing temperature, time, resin, and density affect the pollutants (Lee and Kim 2012; Liu et al. 2012; Candan and Akbulut 2013; Sun et al. 2020). Furthermore, the drying and hot-pressing techniques were helpful in reducing the formaldehyde and VOCs emission from wood-based panels (He et al. 2012). There are some reports on the effects of the adhesive on VOCs and formaldehyde emissions (Navarrete et al. 2013), but most of these studies are related to the low percentage of formaldehyde in urea-formaldehyde resin adhesive and formaldehydefree adhesive, which will decrease the tensile strength of the particleboard and increase the production cost significantly. In addition, heat treatment methods, which evaporate pollutants more quickly by increasing the temperature of the environment, have been reported in some studies (Young et al. 2012; Jiang et al. 2017).

The surface finishing method of wood-based panels is one of the methods of secondary processing of panels to control VOCs and formaldehyde (Kim and Kim 2005; Akkus et al. 2019). Some scholars have studied several surface finishing methods to reduce the release of TVOCs and formaldehyde (Kim et al. 2010). The results showed that different surface finishing methods can lessen TVOCs and formaldehyde in wood-based panels and have proposed that the finish materials and coatings can hinder the path of pollutants' evolution from the wood-based panel. However, the principle of VOCs emissions on the surface of finishing particleboard have not been thoroughly studied, and further analysis of emission ingredients is needed. In this study, several surface finishing materials and water borne coatings were used to treat the particleboards. A small environment chamber, handheld VOCs gas detector, and formaldehyde detectors were used to detect TVOC and formaldehyde. The ingredients of the pollutants released from the finished and unfinished particleboard were analyzed by a gas phase mass spectrometer (GC/MS).

\section{EXPERIMENTAL}

\section{Materials}

E1 poplar particleboards with dimensions of $1220 \mathrm{~mm} \times 2440 \mathrm{~mm} \times 16 \mathrm{~mm}$ were purchased from Suiha Wood Composite Factory, Suihua, China. Table 1 shows the hotpressing parameters of the particleboard. The walnut sliced veneer and pine sliced veneer with thicknesses of $2.5 \mathrm{~mm}$ and $45 \%$ moisture content were purchased from Mudanjiang Hongye Thin Wood Planer, Mudanjiang, China. The density of the walnut sliced veneer was $0.56 \mathrm{~g} / \mathrm{cm}^{3}$, and the density of pine sliced veneer was $0.51 \mathrm{~g} / \mathrm{cm}^{3}$. The $\mathrm{NH}_{4} \mathrm{Cl}$ with $20 \%$ concentration, used as a curing agent, was purchased from Lanxing Chemical Co., Ltd. Jining, China. The high-density polyethylene decorative film with $0.1-\mathrm{mm}$ thickness, 1.28 $\mathrm{g} / \mathrm{cm}^{3}$ density, and melamine impregnated paper with $0.2-\mathrm{mm}$ thickness was obtained from the Songjiang Plywood Factory, Harbin, China. The grammage of melamine-impregnated papers was $80 \mathrm{~g} / \mathrm{m}^{2}$ and $120 \mathrm{~g} / \mathrm{m}^{2}$, respectively. Water-borne polyurethane coating (undercoat, topcoat) and water borne polypropylene coating (undercoat, topcoat) were supplied by Ketian Water borne Technology Co., Ltd., Lanzhou, China.

The urea-formaldehyde resin (UF) adhesive was purchased from Bond Corp., Harbin, China. The condition of the UF adhesive was described as follows: $7.8 \mathrm{pH}$ value, $76.8 \mathrm{~s}$ of curing time, $0.6 \%$ of formaldehyde content, and $51.9 \%$ of solid content. The 
polyvinyl acetate copolymer emulsion (PVAc) adhesive, including $28 \%$ of the solid content and $6.2 \mathrm{pH}$ value, was obtained from the Minglang Rubber Industry, Harbin, China. The industrial flour, used as filler, was purchased from Deyun Chemical Co., Ltd. Suzhou, China.

Table 1. Hot-pressing Parameters of E1 Poplar Particleboard

\begin{tabular}{|c|c|c|c|}
\hline Option & Parameter & Option & Parameter \\
\hline $\begin{array}{l}\text { Hot-pressing temperature } \\
\qquad\left({ }^{\circ} \mathrm{C}\right)\end{array}$ & 190 & $\begin{array}{l}\text { Surface moisture content after sizing } \\
(\%)\end{array}$ & 8.5 to 9.5 \\
\hline Surface pressure (MPa) & $29.5 \mathrm{MPa}$ & $\begin{array}{c}\text { Water content of core layer after } \\
\text { sizing (\%) }\end{array}$ & 8.5 to 10 \\
\hline Unit pressure (MPa) & 35 & $\begin{array}{l}\text { Moisture content of slab after hot } \\
\text { pressing (\%) }\end{array}$ & 6 \\
\hline Hot pressing time (s) & $210 s$ & Solid content of the adhesive (\%) & 60 to 65 \\
\hline Density $\left(\mathrm{g} / \mathrm{cm}^{3}\right)$ & 0.7 & Surface sizing percentage (\%) & 10 \\
\hline Curing agent content (\%) & 1.8 & Core layer sizing percentage (\%) & 90 \\
\hline $\begin{array}{l}\text { Moisture content of the } \\
\text { particle (\%) }\end{array}$ & $1 \%$ to $3 \%$ & Sizing amount $\left(\mathrm{Kg} / \mathrm{m}^{3}\right)$ & 120 \\
\hline
\end{tabular}

\section{Instruments}

The VOCs acquisition device shown in Fig. 1 was developed and designed by Northeast Forestry University (Harbin, China). The acquisition device used to simulate indoor environment includes a small environmental chamber (Northeast Forestry University, Harbin, China), KJG3001 air purifier (Beijing Yadu Environmental Technology Co., Ltd., Beijing, China), and an outlet configuration for collecting exhaust gas from the environmental chamber. The outlet of the environmental chamber is connected to the air inlet of an ANB3025 intelligent vacuum pump (New Weicheng Technology Ltd., Chengdu, China), and the other end is connected to the drying tower. The bottom of the drying tower is filled with calcium chloride as a desiccant to absorb water vapor in the gas. The upper part of the drying tower is filled with activated carbon particles to absorb VOCs. The volume of the small environmental chamber is $0.09 \mathrm{~m}^{3}$. The inner wall is made of polished stainless steel. The air flow is $1.88 \mathrm{~L} \mathrm{~min}$, and the air exchange rate is $1.13 \mathrm{~h}$.

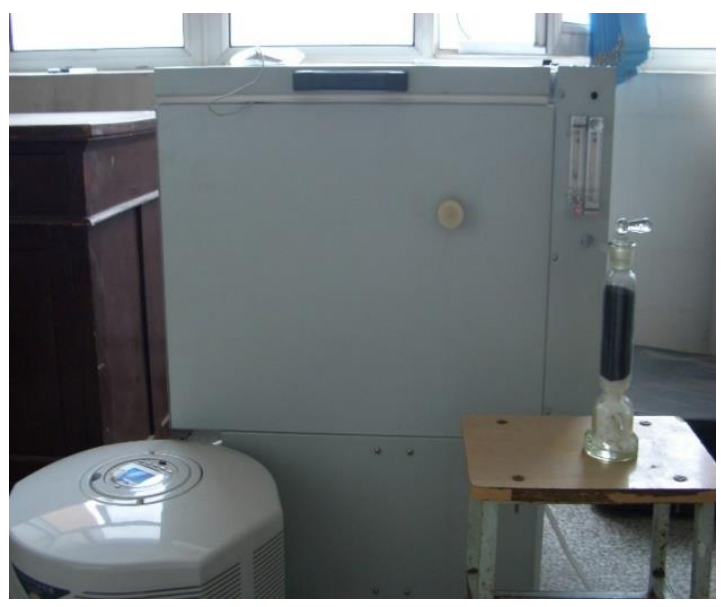

Fig. 1. The VOCs acquisition device 


\section{Preparation of specimens}

The test specimens were prepared according to ASTM D5116-10 (2010) (Wang et al. 2017): the E1 poplar particleboard was sawn into small specimens with dimensions of $230 \mathrm{~mm} \times 240 \mathrm{~mm} \times 16 \mathrm{~mm}$. The aluminum tape was used to seal the edges of the specimen to prevent emissions of the VOCs from the edges. The area of the surface of the test sample that was exposed in the chamber air was $0.09 \mathrm{~m}^{2}$. Then, the specimens were wrapped in polytetrafluoroethylene plastic bags and placed in the refrigerator at $-30{ }^{\circ} \mathrm{C}$.

\section{Methods}

Surface finishing process

The surface of the specimen was sanded with 100-mesh sandpaper to remove the paraffin layer of the base material surface. The $50 \mathrm{~g}$ of UF adhesive, $12.5 \mathrm{~g}$ of PVAc adhesive, $7.5 \mathrm{~g}$ of flour, $15 \mathrm{~g}$ of water, and $0.5 \mathrm{~g}$ of ammonium chloride with $20 \%$ concentration was mixed to prepare the UF/PVAc hybrid adhesive (Gáborík et al. 2016). The weight of the adhesive on each side of particleboard was $8.28 \mathrm{~g}$. After applying the veneer on the base material for $30 \mathrm{~min}$, the specimens were fed into the hot-pressing machine (BY60222/2; Zhengtai Machinery Manufacturing Co., Ltd., Linyi, China) at conditions of $120^{\circ} \mathrm{C}, 1 \mathrm{MPa}$ pressure, and 3 min pressing time (Hu et al. 2005). Melamineimpregnated paper was put on the surface of the base material directly. The hot press parameters of melamine-impregnated paper particleboard were as follows: $185^{\circ} \mathrm{C}, 1 \mathrm{~min}$ pressing time, and 2.0 MPa pressure (Liu and Zhu 2014). High density polyethylene film was attached to the base material without pressure. The $50 \mathrm{~mL}$ polyurethane and polypropylene water-borne coating was diluted with $15 \mathrm{~mL}(30 \%)$ of water, and the calculated density of the water borne coating was $1.02 \mathrm{~g} / \mathrm{cm}^{3}$. The density of the polyurethane emulsion used in the experiment as the undercoat was $1.00 \mathrm{~g} / \mathrm{cm}^{3}$, and 0.98 $\mathrm{g} / \mathrm{cm}^{3}$ was used as the topcoat. $100 \mathrm{~g} / \mathrm{m}^{2}$ of water-borne coating was evenly applied to the sample with a wire rod applicator. The undercoats and topcoats were applied separately.

\section{TVOC and formaldehyde concentration detection}

The airtight environment chamber method was used for the concentration detection of TVOC and formaldehyde. Before each experiment, the small environment chamber was cleaned with distilled water, dried, and run for $1 \mathrm{~h}$ without load. The parameters of the environment chamber were set as follows: the ambient temperature was $23 \pm 0.5^{\circ} \mathrm{C}$, and the relative humidity was $45 \% \pm 5 \%$. The TVOC concentration in the cabin was less than $10 \mathrm{~kg}$ $/ \mathrm{m}^{3}$. The gradual emission of TVOC and formaldehyde concentration of the specimen was detected in the first $6 \mathrm{~h}$, and the total concentration after $24 \mathrm{~h}$. The gas outlet of the small environment chamber was separated by a shunt tube, and the concentration of TVOC and formaldehyde are measured from a ppbRAE Plus handheld VOC detector (RAE Systems, Inc., San Jose, CA, USA) and the formaldehyde concentration from an INTERSCAN 4160 formaldehyde analyzer (Interscan Co., Ltd., Simi Valley, Canada).

\section{VOCs composition analysis}

The finished specimen was placed in a 15-L glass dryer on the side with Vaseline coating to prevent air leakage. After $24 \mathrm{~h}$ of airtight sampling, the dryer was connected to the inlet of a smart vacuum pump that was connected to the drying tower. The upperpart of the drying tower was filled with $300 \mathrm{~g}$ of activated carbon particles used for absorbing VOCs for $24 \mathrm{~h}$. During pumping, the drier stopper was slightly aerated to maintain a positive pressure to absorb VOCs in the drier. Then the activated carbon with adsorbed 
VOCs was soaked with dichloromethane as a solvent for 20 to $30 \mathrm{~min}$. According to similar intermiscibility, the adsorbed VOCs were desorbed into the solvent. The activated carbon immersed in the solvent was filtered, and the filtrate was concentrated by a rotary evaporator to prepare a sample for GC/MS detection (Uchiyama et al. 1999).

The components of the volatiles emissions from particleboards were analyzed using a GC/MS (Trace DSQ II; Thermo Scientific, Waltham, MA, USA) system consisting of a Trace gas chromatographic and a DSQ ${ }^{\circ} \mathrm{C}$ mass selective detector. A TR-V1 capillary column with $0.25-\mathrm{mm}$ ID, $30 \mathrm{~m}$, and $1.4 \mu \mathrm{m}$ film thickness was used to separate the chemical compounds. The GC inlet temperature was set at $250^{\circ} \mathrm{C}$ with a split ratio of 1:40. The GC oven temperature started at $40{ }^{\circ} \mathrm{C}$ and was held for $2 \mathrm{~min}$. The temperature program ranged from 40 to $150{ }^{\circ} \mathrm{C}$ at a rate of $4{ }^{\circ} \mathrm{C}$ per min and was then heated to $250{ }^{\circ} \mathrm{C}$ at a rate of $10^{\circ} \mathrm{C}$ per min. The ionizer voltage of the MS detector was set at $70 \mathrm{eV}$, and the temperature was set to $230{ }^{\circ} \mathrm{C}$. The mass scan range was 40 to $450 \mathrm{amu}$. The carrier gas was high-purity helium with a flow rate at $1.0 \mathrm{~mL} / \mathrm{min}$. The interface temperature was set at $270{ }^{\circ} \mathrm{C}$. The compounds were identified by the retention time and comparison with mass spectra library. The concentrations of volatile components were quantified with the peak area of Toluene-D8. In the experimental analysis, the software of the GC-MS was used to analyze the total ion flow chromatogram, and the NIST and WILEY spectrum library were used to search and determine the main components of volatiles. Finally, the compounds, similarity, and mass fraction of volatiles from particleboards were analyzed.

\section{RESULTS AND DISCUSSION}

\section{Effects of Surface Finishing Methods on the TVOC Emission of Particleboard}

As shown in Fig. 2, different surface finishing methods had a remarkable effect on TVOC concentration in $6 \mathrm{~h}$.

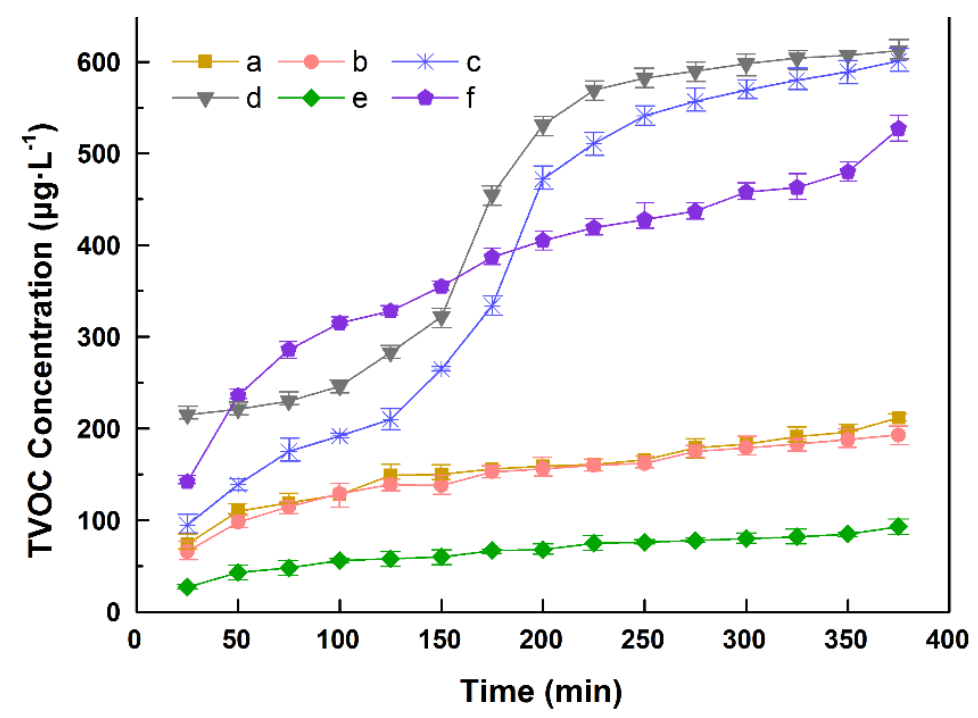

Fig. 2. TVOC emission concentration curves of the finishing samples: (a) finishing particleboard with melamine paper $\left(80 \mathrm{~g} / \mathrm{m}^{2}\right)$; (b) finishing particleboard with melamine paper $\left(120 \mathrm{~g} / \mathrm{m}^{2}\right)$; (c) finishing particleboard with pine veneer; (d) finishing particleboard with walnut veneer; (e) finishing particleboard with high-density polyethylene film; and (f) unfinished particleboard 
Compared with unfinished particleboard, a $84.2 \%$ reduction of TVOC was achieved with the finishing of high-density polyethylene film, followed by melamineimpregnated paper. Melamine-impregnated paper with $120 \mathrm{~g} / \mathrm{m}^{2}$ grammage, which means the weight of paper expressed as grams per square meter selected in the experiment, had a better barrier effect than that of melamine-impregnated paper with $80 \mathrm{~g} / \mathrm{m}^{2}$ grammage. However, the TVOC concentration of pine-veneered and walnut-veneered particleboard at $6 \mathrm{~h}$ was slightly higher than that of unfinished particleboard, which indicated that the VOCs of UF/PVAc hybrid adhesive affected the results. For the hardwood species with few ducts, such as walnut, the tylosis are quite rich, and the parenchyma cells are densely packed, resulting in the low concentration of walnut-veneered particleboard. For soft-wood species, such as pine veneer, because pine itself is rich in resin channels, it needs to be digested to remove the resin, and the retention of resin channels increases the degree of gas volatilization. Therefore, the TVOC concentration of pine-veneered particleboard was always higher than that of walnut-veneered particleboard.

Figure 3 shows the TVOC emission concentration of the finishing samples after 24 $\mathrm{h}$. The barrier effect of various finishing methods by the dryer method was displayed in the following descending order: the high-density polyethylene film, melamine-impregnated paper with $120 \mathrm{~g} / \mathrm{m}^{2}$ grammage, the melamine-impregnated paper with $80 \mathrm{~g} / \mathrm{m}^{2}$ grammage, then the pine veneer, and finally walnut veneer. The initial concentration of pine- and walnut-veneered particleboard was lower than that of unfinished particleboard, showing that the TVOC emission rate of unfinished particleboard was higher in earlier stages of the experiment. Due to the use of adhesives for finishing, the TVOC concentration of veneered particleboard was higher than that of unfinished particleboard as time passed. However, the later concentration of the unfinished particleboard exceeded that of the veneered particleboard, indicating that the influence of adhesives was weakened, and its role as a barrier to VOCs dominated after $24 \mathrm{~h}$. In addition, the TVOC concentration of the veneered particleboard at hour 24 was approximately $50 \%$ lower than that of the unfinished particleboard.

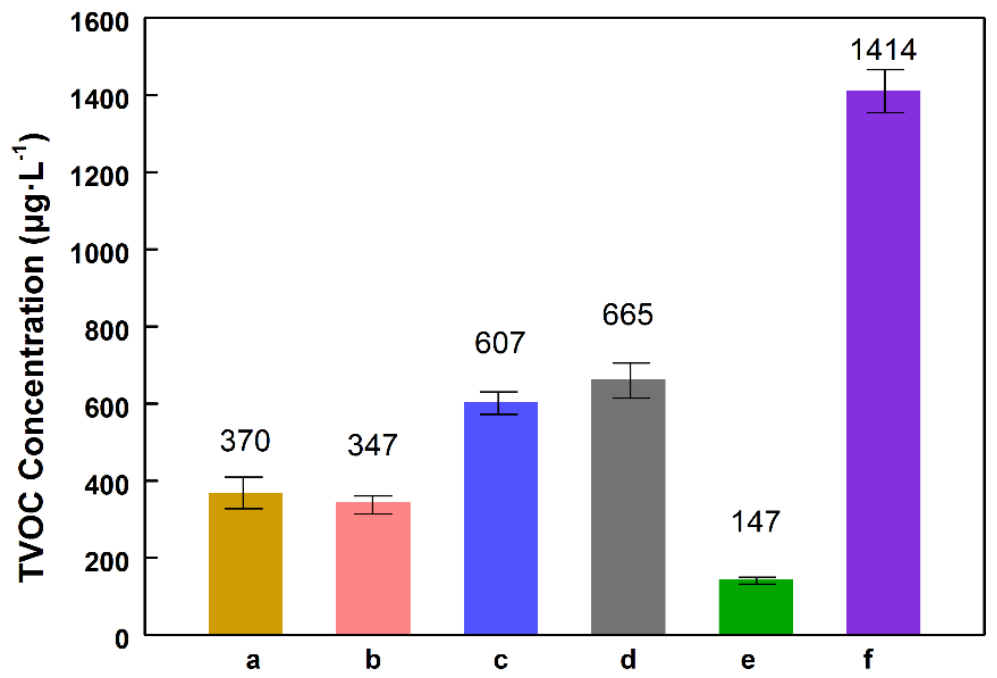

Fig. 3. TVOC emission concentration of the finishing samples after $24 \mathrm{~h}$ : (a) finishing particleboard with melamine paper $\left(80 \mathrm{~g} / \mathrm{m}^{2}\right)$; (b) finishing particleboard with melamine paper $\left(120 \mathrm{~g} / \mathrm{m}^{2}\right)$; (c) finishing particleboard with pine veneer; (d) finishing particleboard with walnut veneer; (e) finishing particleboard with high-density polyethylene film; and (f) unfinished particleboard 


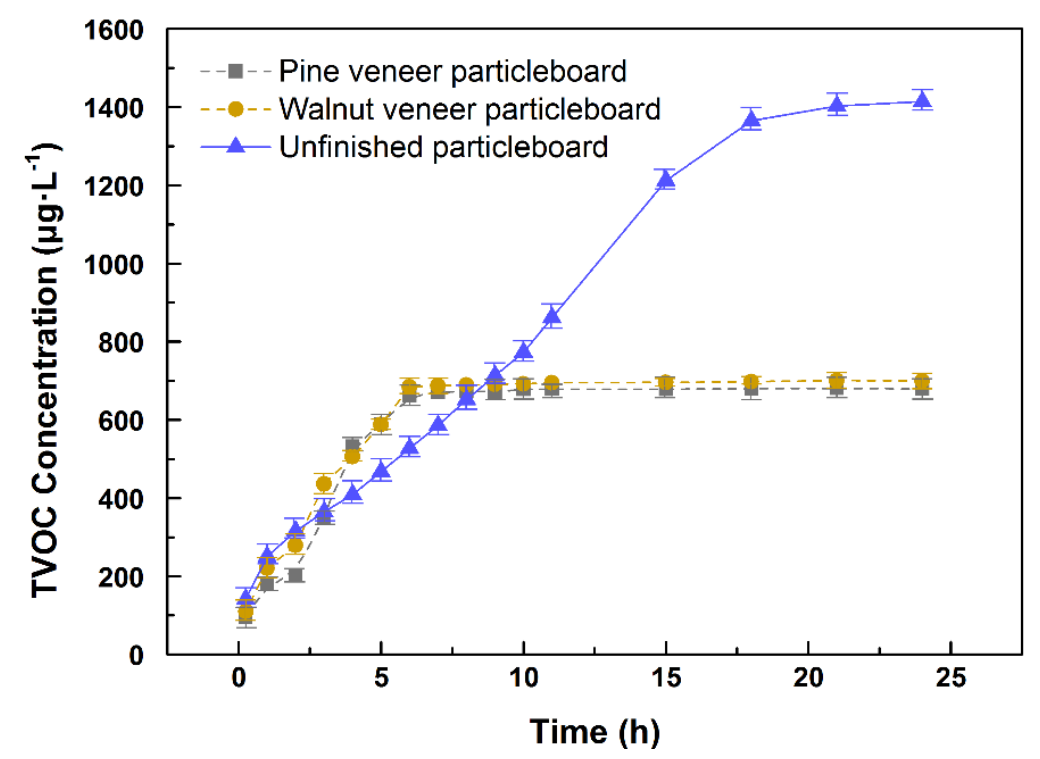

Fig. 4. TVOC emission concentration curves of the veneered samples and unfinished sample

To specifically research the emission trend of veneered particleboard, the TVOC concentration of the veneer finishing method and unfinished particles each hour is shown in Fig. 4. Based on the comparison of the TVOC emission curves of veneered and unfinished particleboard, the TVOC concentration emission of veneered particleboard can be divided into three stages in $24 \mathrm{~h}$ : earlier stage, medium stage, and later stage.

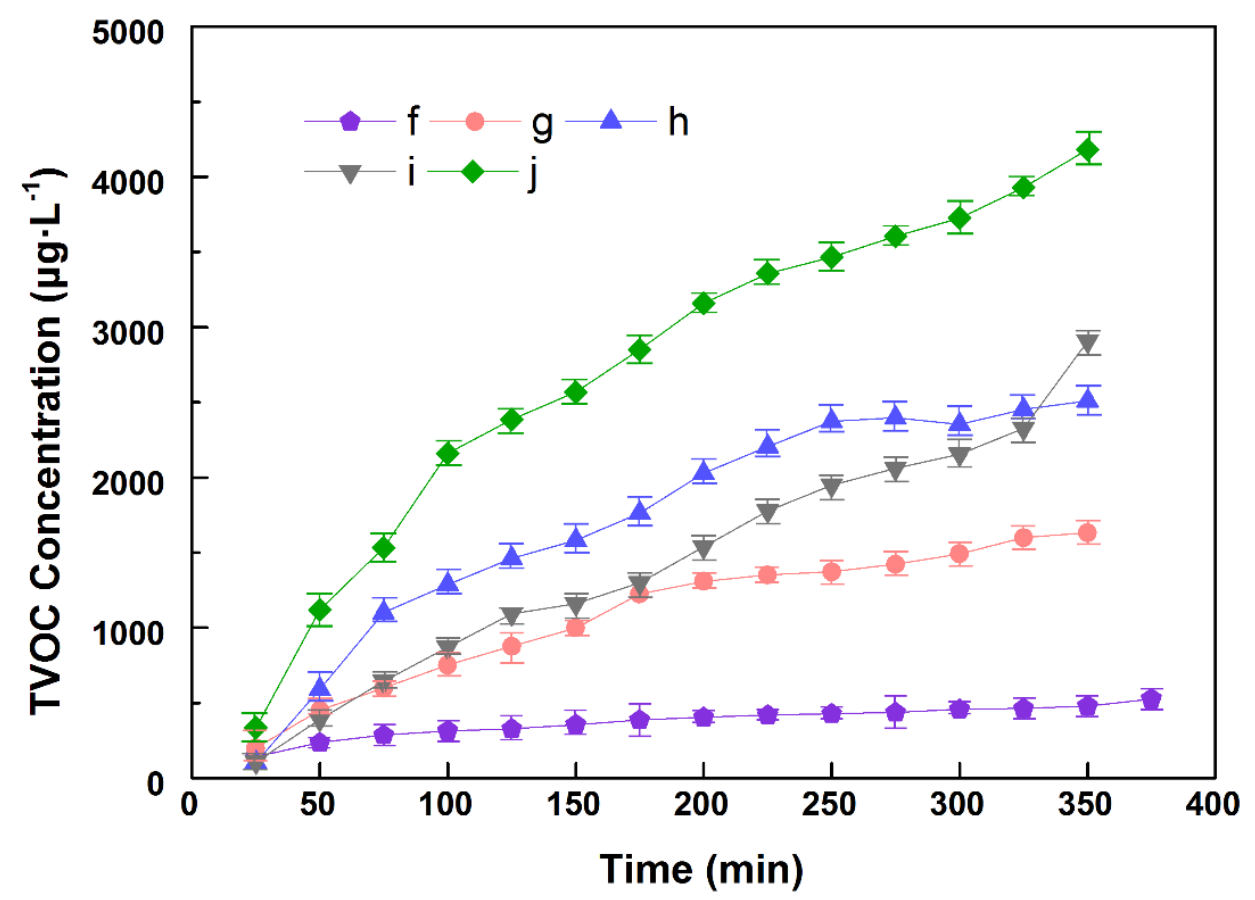

Fig. 5. TVOC emission concentration curves of the water borne paint coating samples: (f) TVOC emission concentration of unfinished particleboard; (g) water-borne polypropylene emulsion undercoat particleboard; (h) water-borne polypropylene emulsion topcoat particleboard; (i) water-borne polyurethane emulsion undercoat particleboard; and (j) water-borne polyurethane emulsion topcoat particleboard 
The TVOC concentration of the thin wood veneered particleboard was lower than that of the unfinished particleboard at the earlier stage. From the $3^{\text {rd }}$ hour to the $10^{\text {th }}$ hour, the TVOC concentration emission rate of the veneered particleboard was slightly faster than that of the unfinished particleboard, for the veneer adhesive volatilized VOCs in this period. From the $10^{\text {th }}$ hour to the $24^{\text {th }}$ hour, the effect of the veneer adhesive on the TVOC concentration was weakened, and the barrier property occupied a dominant position. It was obvious that the wood veneer still had a barrier effect on the emission of TVOC after $10 \mathrm{~h}$, and the TVOC concentration of veneered particleboard at the $24^{\text {th }}$ hour was approximately $50 \%$ lower than that of the unfinished particleboard.

The VOC emission concentration of the finishing samples after $24 \mathrm{~h}$ is shown in Fig. 5. Water-borne coatings were shown to be highly volatile and to have a long drying time, resulting in a higher TVOC concentration for the water borne coating samples. Among them, the TVOC concentration released by the undercoat-coated particleboard was slightly lower than that of the top-coated particleboard. The water-borne polypropylene coating particleboard had a better barrier effect of harmful pollutants than the water borne polyurethane coating. Judging from the results of analysis, the decorative materials decorated with water borne paints should be ventilated at an early stage to accelerate the drying of water borne coatings and lessen the emission of VOCs.

\section{Effects of Finishing Methods on the Formaldehyde Emission of Particleboard}

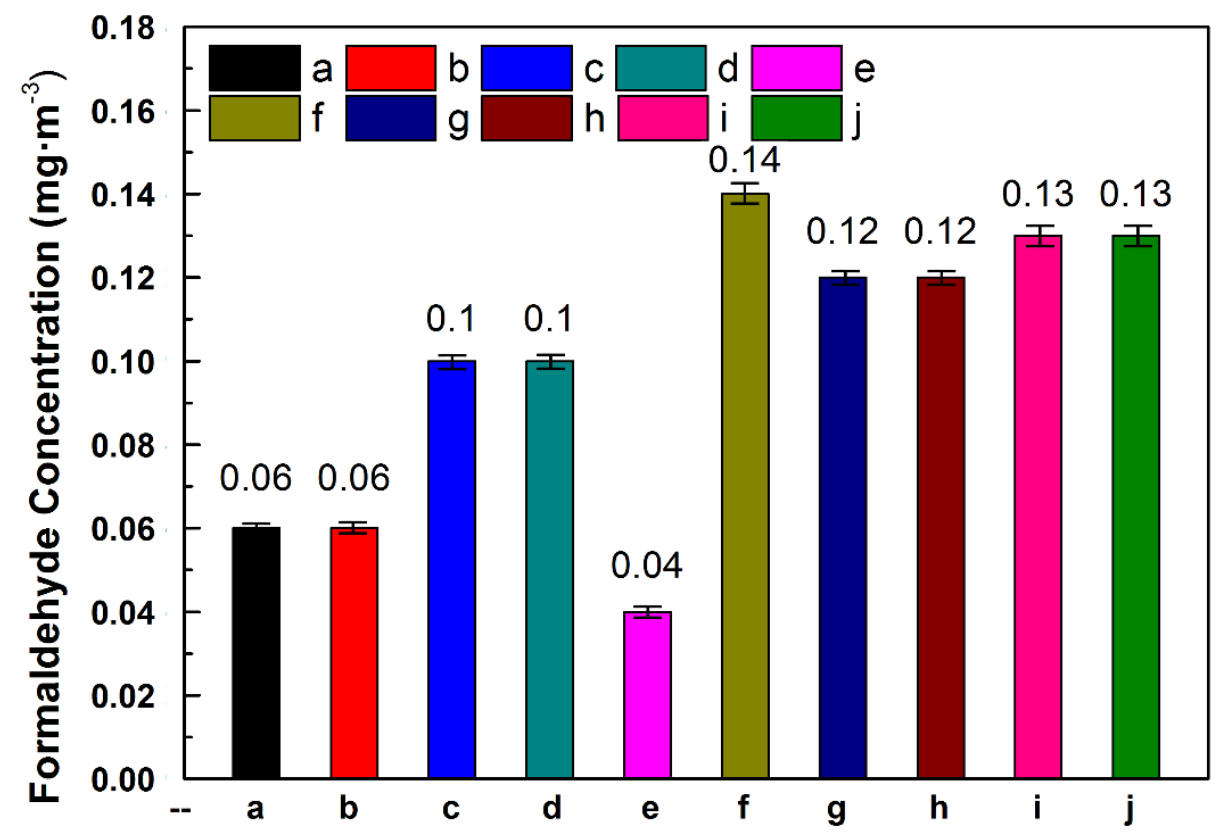

Fig. 6. Formaldehyde emission concentration of the finishing samples after $24 \mathrm{~h}$ : (a) finishing particleboard with melamine paper $\left(80 \mathrm{~g} / \mathrm{m}^{2}\right)$; (b) finishing particleboard with melamine paper $\left(120 \mathrm{~g} / \mathrm{m}^{2}\right)$; (c) finishing particleboard with pine veneer; (d) finishing particleboard with walnut veneer; (e) finishing particleboard with high-density polyethylene film; (f) unfinished particleboard; (g) water-borne polypropylene emulsion undercoat particleboard; (h) water-borne polypropylene emulsion topcoat particleboard; (i) water-borne polyurethane emulsion undercoat particleboard; and (j) F water-borne polyurethane emulsion topcoat particleboard 
Figure 6 shows formaldehyde emission concentration of the finishing and coating specimen after $24 \mathrm{~h}$. The average formaldehyde concentration released from the finishing samples was lower than that of the unfinished board, indicating that different finishing methods had a barrier effect on formaldehyde. Among them, the high-density polyethylene film finishing method worked best, with a sealing effect of more than $70 \%$. The sealing effect of the melamine impregnated paper finishing method was $57.1 \%$, and the sealing effect of the veneer finishing method was $28.6 \%$. In addition, the water-borne coating had a low sealing effect. The water borne topcoat and undercoat only sealed $14.3 \%$ and $4.1 \%$ of formaldehyde compared to unfinished particleboard, respectively.

\section{Effects of Pine Veneer on the Composites of Particleboard Volatiles by GC/MS}

After airtight conditions were maintained for $24 \mathrm{~h}$, a smart vacuum pump was used to allow the gas in the closed container to enter the activated carbon of drying tower for adsorbing volatile gas. Then, the activated carbon soaked in the solvent was filtered, and the filtrate was concentrated by the rotary evaporator to prepare the sample. The specific components and contents of volatiles were analyzed by GC/MS. In the experimental analysis, the instrument's own software was used to analyze the total ion flow chromatogram, and NIST and WILEY spectrum library of GC/MS were used to retrieve and qualitatively determine the main components of volatiles. Therefore, the compounds, similarity, and mass fraction in the volatiles of wood veneered particleboard were obtained through analysis.

The results of the GC/MS analysis in Fig. 7 were converted into the experimental results of the ingredients and percentages of the compounds contained in the samples. The main ingredients that were detected in each chemical substance type and the content percentage are shown in Fig. 8 and Table 2. The main volatiles ingredients were aromatic, alkane, terpene substances, and a tiny amount of quinones, ketones, esters, and acids. The 21 ingredients were detected in unfinished particleboard, and 15 ingredients were detected in veneered particleboard. The amount of volatiles in veneered particleboard was less than that in unfinished particleboard. Six compounds were not detected from veneered particleboard, indicating that these six substances were blocked by the veneer material. In addition to a few aromatic and alkane substances, veneer can effectively control volatiles volatilization of particleboard base material and lessen the emission of more than $50 \%$ of the volatiles content. However, the reduction of a small number of aromatic and alkane ingredients released in veneered particleboard did not noticeably demonstrate that volatilization of alkanes and aromatic family substances were the joint effect of veneer, adhesive, and particleboard base material.

The main percentage of volatiles in unfinished particleboard was phthalic acid (2ethylhexyl) ester accounting for $34.2 \%$ of the total volatile organic matter content, which was phthalic acid ester derivatives added to the adhesive as plasticizer. Phthalic acid (2ethylhexyl) ester and its derivatives, which are generally adsorbed in particleboard base material, and the solid adhesives ingredients are highly toxic and are slowly released into the environment. Alkanes, terpenes, and aromatic compounds are the main components of lignin in particleboard base material, which are cracked in the process of hot pressing and high temperature. During the hot-pressing process, most alkanes and aromatic hydrocarbons are volatilized due to the rising temperature, but some of them were still adsorbed in the particleboard and released slowly. The content of aldehydes, acids, and ketones were low because of their fast volatilization in hot pressing. 


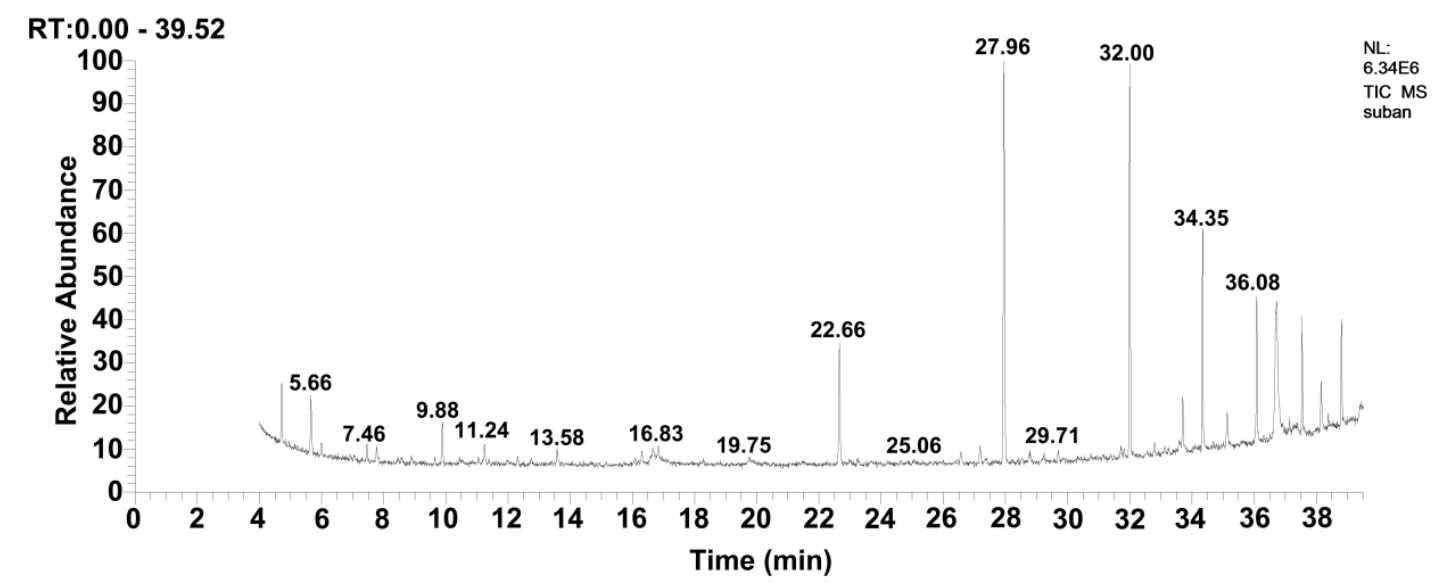

(a)

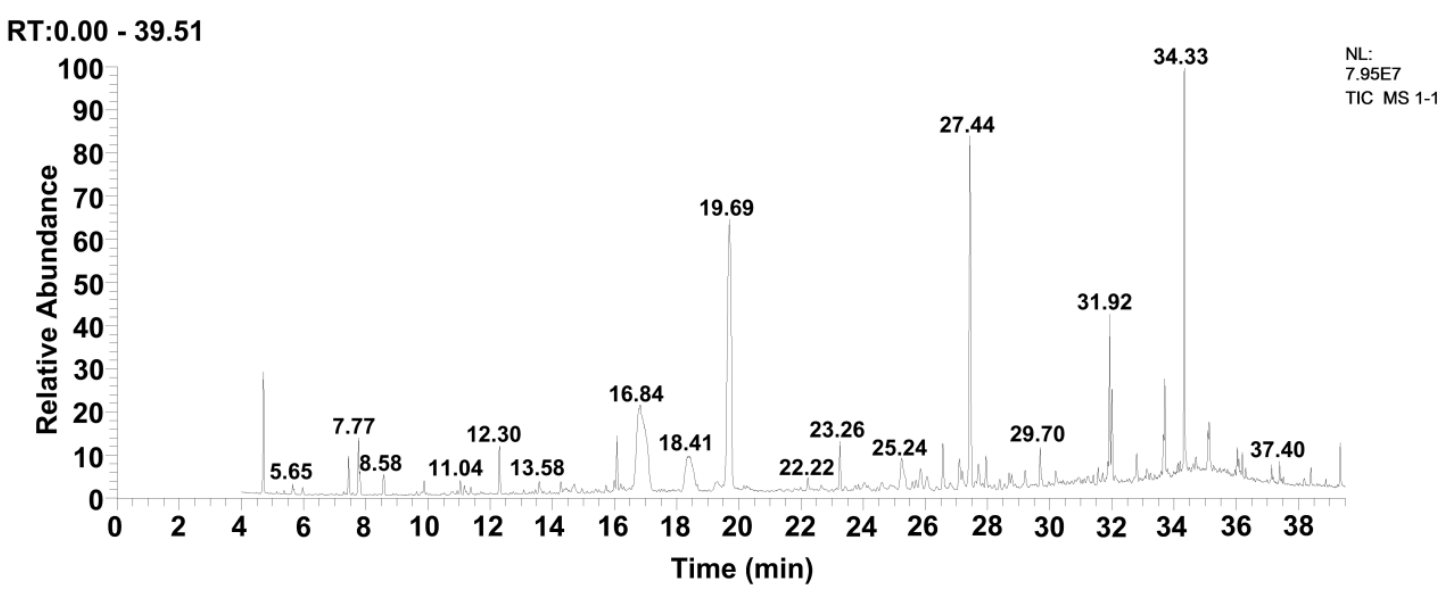

(b)

Fig. 7. GC/MS analysis of volatiles on veneered particleboard and unfinished particleboard: (a) unfinished particleboard and (b) veneered particleboard

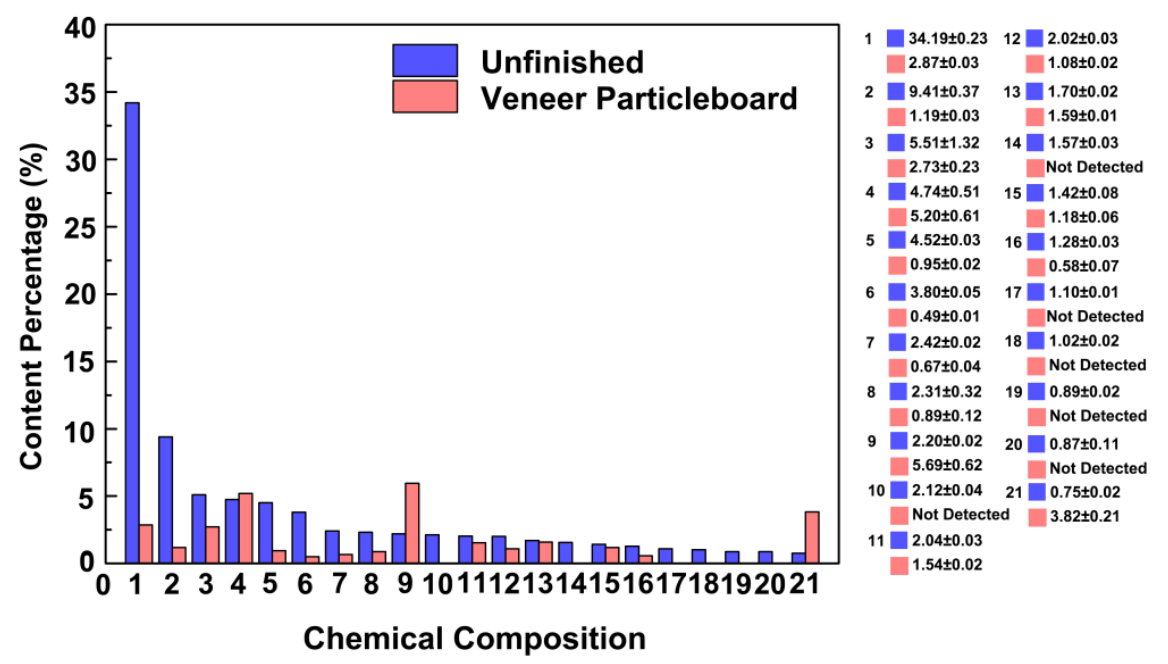

Fig. 8. The main volatile components and content percentage of veneered particleboard and unfinished particleboard 
Table 2. Main Volatile Components and Content Percentage of Veneered Particleboard and Unfinished Particleboard.

\begin{tabular}{|c|c|c|c|}
\hline \multirow[t]{2}{*}{ Sample } & \multirow[t]{2}{*}{ Chemical Composition } & \multicolumn{2}{|c|}{ Content Percentage (\%) ${ }^{a}$} \\
\hline & & Unfinished & $\begin{array}{c}\text { Veneered } \\
\text { Particleboard }\end{array}$ \\
\hline 1 & Phthalic acid (2-ethylhexyl) ester* & $34.19 \pm 0.23$ & $2.87 \pm 0.03$ \\
\hline 2 & 2,6, 10-trimethyltetradecane & $9.41 \pm 0.37$ & $1.19 \pm 0.03$ \\
\hline 3 & Toluene & $5.11 \pm 1.32$ & $2.73 \pm 0.23$ \\
\hline 4 & $2,6,10,14$-tetramethylhexadecane* & $4.74 \pm 0.51$ & $5.2 \pm 0.61$ \\
\hline 5 & $\beta$-pinene & $4.52 \pm 0.03$ & $0.95 \pm 0.02$ \\
\hline 6 & Hexanal & $3.8 \pm 0.05$ & $0.49 \pm 0.01$ \\
\hline 7 & Bis-succinate-2-methylpropyl & $2.42 \pm 0.02$ & $0.67 \pm 0.04$ \\
\hline 8 & Undecane & $2.31 \pm 0.32$ & $0.89 \pm 0.12$ \\
\hline 9 & O-xylene & $2.2 \pm 0.02$ & $5.96 \pm 0.62$ \\
\hline 10 & Furan ketone & $2.12 \pm 0.04$ & Not detected \\
\hline 11 & 2, 5-ditert-butyl benzoquinone ${ }^{*}$ & $2.04 \pm 0.03$ & $1.54 \pm 0.02$ \\
\hline 12 & 1-methyl-5 -(1-methyl vinyl)cyclohexene & $2.02 \pm 0.03$ & $1.08 \pm 0.02$ \\
\hline 13 & Ethyl benzene & $1.7 \pm 0.02$ & $1.59 \pm 0.01$ \\
\hline 14 & $\begin{array}{c}\text { Bis -2- methyl succinic acid -1- methyl } \\
\text { propyl ester }\end{array}$ & $1.57 \pm 0.03$ & Not detected \\
\hline 15 & 5, 8-diethyldodecane & $1.42 \pm 0.08$ & $1.18 \pm 0.06$ \\
\hline 16 & 9-hexyl-heptadecane* & $1.28 \pm 0.03$ & $0.58 \pm 0.07$ \\
\hline 17 & 2-methyl-cyclopentanone & $1.1 \pm 0.01$ & Not detected \\
\hline 18 & Basilene & $1.02 \pm 0.02$ & Not detected \\
\hline 19 & Ethyl p-ethoxy benzoate & $0.89 \pm 0.02$ & Not detected \\
\hline 20 & 2, 6-ditert-butyl para-cresol* & $0.87 \pm 0.11$ & Not detected \\
\hline 21 & Castor acid & $0.75 \pm 0.02$ & $3.82 \pm 0.21$ \\
\hline
\end{tabular}

${ }^{*}$ Compounds with boiling points greater than $260{ }^{\circ} \mathrm{C}$ (plasticizers)

aThe results are given as averages and standard deviations from the mean values

\section{CONCLUSIONS}

1. The changes of total volatile organic compounds (TVOC) and formaldehyde concentrations in poplar wood particleboard with different surface materials were studied under airtight conditions. The results showed that different finishing materials of wood-based panels could control the emission of TVOC (except for waterborne paint) and formaldehyde in particleboard. The HDPE film had the best sealing effect, showing an $84.2 \%$ reduction of TVOC and $71.4 \%$ reduction of formaldehyde. The volatile content of waterborne paint was large, which had a great influence on TVOC emission.

2. The barrier effect of melamine-impregnated paper with $120 \mathrm{~g} / \mathrm{m}^{2}$ grammage was better than that of melamine-impregnated paper with $80 \mathrm{~g} / \mathrm{m}^{2}$ grammage. The reductions of formaldehyde emission of pine wood veneer and walnut were equal, but reduction of TVOC emissions of pine was better after $24 \mathrm{~h}$. Compared to the walnut veneer, the reduction effect of the pine veneered particleboard was better due to the porosity of pine. Water borne topcoat and undercoat only sealed $14.3 \%$ and $4.1 \%$, respectively, of formaldehyde compared to unfinished particleboard. The TVOC released from the 
undercoated particleboard was slightly lower than that from the top-coated particleboard.

3. The volatiles emission ingredients of veneered particleboard and unfinished particleboard showed that the veneer method sufficiently reduced the volatiles emission of particleboard, except for a few benzene and alkanes. The amount of volatiles in veneered particleboard was less than that in unfinished particleboard. Alkanes, aromatic hydrocarbons, and terpenes were mainly derived from particleboard base materials. The highest mass fraction of the unfinished particleboard was phthalic acid (2-ethylhexyl) ester (34.19\%), while the highest mass fraction of the veneered particleboard was o-xylene (5.96\%).

\section{ACKNOWLEDGMENTS}

This work was financially supported by the National Natural Science Foundation of China (Grant No. 31901243). Feng Chen and Jun Shen conceived of, designed, and performed the experiments. Xinghua Xia and Feng Chen analyzed and discussed the data. Feng Chen wrote the manuscript, with revisions by Xinghua Xia.

\section{REFERENCES CITED}

Akkus, M., Akbulut, T., and Candan, Z. (2019). "Application of electrostatic powder coating on wood composite panels using a cooling method. Part 1: Investigation of water intake, abrasion, scratch resistance, and adhesion strength," BioResources 14(4), 9557-9574. DOI: 10.15376/biores.14.4.9557-9574

ASTM D5116-10 (2010). "Standard guide for small-scale environmental chamber determinations of organic emissions from indoor materials/products," ASTM International, West Conshohocken, PA, USA.

Candan, Z., and Akbulut, T. (2013). "Developing environmentally friendly wood composite panels by nanotechnology," BioResources 8(3), 3590-3598. DOI: 10.15376/biores.8.3.3590-3598

Chi, C., Chen, W., Guo, M., Weng, M., Yan, G., and Shen, X. (2016). "Law and features of TVOC and formaldehyde pollution in urban indoor air," Atmos. Environ. 132, 8590. DOI: 10.1016/j.atmosenv.2016.02.043

Du, Z. J., Mo, J. H., and Zhang, Y. P. (2014). "Risk assessment of population inhalation exposure to volatile organic compounds and carbonyls in urban China," Environ. Int. 73, 33-45. DOI: 10.1016/j.envint.2014.06.014

Gáborík, J., Gaff, M., Ruman, D., Záborský, V., Kašíčková, V., and Sikora, A. (2016). "Adhesive as a factor affecting the properties of laminated wood," BioResources 11(4), 10565-10574. DOI: 10.15376/biores.11.4.10565-10574

He, Z., Zhang, Y., and Wei, W. (2012). "Formaldehyde and VOC emissions at different manufacturing stages of wood-based panels," Build. Environ. 47, 197-204. DOI: 10.1016/j.buildenv.2011.07.023

Hu, Y., Wang, F., Gu, J., Liu, Y., and Nakao, T. (2005). "Nondestructive test and prediction of modulus of elasticity of veneer-overlaid particleboard composite," Wood Sci. Technol. 39(6), 439-447. DOI: 10.1007/s00226-005-0013-1 
Jiang, C., Li, D., Zhang, P., Li, J., Wang, J., and Yu, J. (2017). "Formaldehyde and volatile organic compound (VOC) emissions from particleboard: Identification of odorous compounds and effects of heat treatment," Build. Environ. 117, 118-126. DOI: 10.1016/j.buildenv.2017.03.004

Kim, S. (2010). "Control of formaldehyde and TVOC emission from wood-based flooring composites at various manufacturing processes by surface finishing," $J$. Hazard. Mater. 176(1-3), 14-19. DOI: 10.1016/j.jhazmat.2009.03.113

Kim, S., and Kim, H. J. (2005). "Comparison of formaldehyde emission from building finishing materials at various temperatures in under heating system, ONDOL," Indoor Air 15(5), 317-325. DOI: 10.1111/j.1600-0668.2005. 00368.x

Lee, Y. K., and Kim, H. J. (2012). "The effect of temperature on VOCs and carbonyl compounds emission from wooden flooring by thermal extractor test method," Build. Environ. 53, 95-99. DOI: 10.1016/j.buildenv.2011.10.016

Liang, W. H., Lv, M. Q., and Yang, X. D. (2016). "The combined effects of temperature and humidity on initial emittable formaldehyde concentration of a medium-density fiberboard," Build. Environ. 98, 80-88. DOI: 10.1016/j.buildenv.2015.12.024

Liu, Y., Shen, J., and Zhu, X. D. (2012). "Optimization of processing parameters for low VOC emissions of wood-based panels," Appl. Mech. Mater. 148-149, 130-133. DOI: 10.4028/www.scientific.net/AMM.148-149.130

Liu, Y., and Zhu, X. (2014). "Measurement of formaldehyde and VOCs emissions from wood-based panels with nanomaterial-added melamine-impregnated paper," Constr. Build. Mater. 66, 132-137. DOI: 10.1016/j.conbuildmat.2014.05.088

Mølhave, L., Clausen, G., Berglund, B., De Ceaurriz, J., Kettrup, A., Lindvall, T., Maroni, M., Pickering, A. C., Risse, U., Rothweiler, H., et al. (1997). "Total volatile organic compounds (TVOC) in indoor air quality investigations," Indoor Air 7(4), 225-240. DOI: 10.1111/j.1600-0668.1997.00002.x

Navarrete, P., Kebbi, Z., Michenot, F., Lemonon, J., Rogaume, C., Masson, E., Rogaume, Y., and Pizzi, A. (2013). "Formaldehyde and VOCs emissions from bioparticleboards," J. Adhes. Sci. Technol. 27(7), 748-762. DOI:

10.1080/01694243.2012.727149

Niu, H., Mo, Z., Shao, M., Lu, S., and Xie, S. (2016). "Screening the emission sources of volatile organic compounds (VOCs) in China by multi-effects evaluation," Front. Env. Sci. Eng. 10(5), Article number 1. DOI: 10.1007/s11783-016-0828-z

Norback, D. (2009). "An update on sick building syndrome," Curr. Opin. Allergy Cl. 9(1), 55-59. DOI: 10.1097/ACI.0b013e32831f8f08

Rudnicka, J., Kowalkowski, T., and Buszewski, B. (2019). "Searching for selected VOCs in human breath samples as potential markers of lung cancer," Lung Cancer 135, 123-129. DOI: 10.1016/j.lungcan.2019.02.012

Sun, S., Zhao, Z., and Shen, J. (2020). "Effects of the manufacturing conditions on the VOCs emissions of particleboard," BioResources 15(1), 1074-1084. DOI: 10.15376/biores.15.1.1074-1084

Uchiyama, S., Asai, M., and Hasegawa, S. (1999). "A sensitive diffusion sampler for the determination of volatile organic compounds in ambient air," Atmos. Environ. 33(12), 1913-1920. DOI: 10.1016/S1352-2310(98)00208-8

Wang, Q.-F., Shen, J., Zhang, Y., and Liu, W.-J. (2017). "Influence of environmental factors on volatile organic compound emissions from plywood tested by a rapid detection method," Forest Prod. J. 67(1-2), 120-125. DOI: 10.13073/FPJ-D-1600008 
Yrieix, C., Dulaurent, A., Laffargue, C., Maupetit, F., Pacary, T., and Uhde, E. (2010). "Characterization of VOC and formaldehyde emissions from a wood-based panel: Results from an inter-laboratory comparison," Chemosphere 79(4), 414-419. DOI: 10.1016/j.chemosphere.2010.01.062

Zhao, Z. Y., Hayashi, S., Xu, W., Wu, Z. H., Tanaka, S., Sun, S. J., Zhang, M., Kanayama, K., and Umemura, K. (2018). "A novel eco-friendly wood adhesive composed by sucrose and ammonium dihydrogen phosphate," Polymers-Basel 10(11), 1251-1265. DOI: 10.3390/polym10111251

Article submitted: February 13, 2020; Peer review completed: May 3, 2020; Revised version received and accepted: May 16, 2020; Published: May 27, 2020.

DOI: $10.15376 /$ biores.15.3.5450-5463 